\title{
Application possibilities of the low-temperature repairs on creep-resistance turbine components from material GX23CrMoV12-1
}

\author{
Jaromir Moravec ${ }^{1}$, Iva Novakova ${ }^{1,}{ }^{*}$, Jiri Sobotka ${ }^{1}$, Tomasz Kik ${ }^{2}$ \\ ${ }^{1}$ Technical University of Liberec. Studentská 2, 46117 Liberec 1. Czech Republic \\ ${ }^{2}$ Silesian University of Technology, Welding Department, Konarskiego 18A, Gliwice, Poland
}

\begin{abstract}
Papers deals with the problems of repairs at new and also already loaded components of steam and gas turbines. Generally, it is about welding repairs at valve and turbine chambers, transmitters, vane carriers, tripping valve body and so on. There are both technological defects caused by casting (e.g. shrinkage cavities, misruns, porosity and cracks) and defects caused by operation (thermal-stress fatigue, incorrect method of operation, etc.). Many of the mentioned defects take effect not until the final technological method - mostly at machining. However, in this production phase it is not possible to get form the supplier new production elements due to economical and also delivery time reasons. All of that results in delay of production and penalty. As the major aim of this paper, there was to find such repairs techniques which can ensure serviceability of mentioned devices under the standard regime. In these cases is needed to use much lower tempering temperature than under the standard production, mainly because of necessity to eliminate deformation caused by heating of part that is not possible to be subsequently removed by machining.
\end{abstract}

Keywords: Welding, Heat Treatment, GX23CrMoV12-1, Repairing, Strengthening

\section{Introduction}

Different types of defects can negatively influence behavior of creep resistance materials especially at production and running of casted turbine components. These defects are generally caused either by used production technologies or due to the subsequent operational loading. Nevertheless, these production defects are very difficult to be removed because these materials and products of them are typical of e.g. their highly-alloying, complex shape or abnormal dimensions of casted parts. [1,2] Some of these defects (the visual ones) are repaired directly in the foundries with subsequent specified heat treatment of the whole part in furnace (for martensitic steels tempering at temperatures 710 up to $740^{\circ} \mathrm{C}$ ). Moreover, ultrasonic and eddy current NDT is used during visual inspection of every part. $[3,4]$ However, there are defects that can't be detected during visual inspection. These defects are generally detected at subsequent technological operations, mainly during/after machining when the given part already has the final assembly dimensions. Nevertheless, generally

\footnotetext{
* Corresponding author: iva.novakova@tul.cz

Reviewers: Jozef Meško, Daniela Kalincová
} 
during machining can be detected (or even made) other defects as e.g. are cracks in the zones of local stress waves. Beside the mentioned types of defects can be at energy devices detected also defects caused by operational conditions (parameters and purity of steam, blackouts, starting rates and so on), eventually by infringement of the specified operational parameters by operator (e.g. unauthorized use or manipulation). [5,6]

There are generally used covered electrodes (111 acc. to ISO 4063) to repair such kind of defects. With such approach, there is needed to carry out welding with pre-heating and the whole part (or just area to be repaired) is heat treated after welding. If the part dimensions are not abnormal, heat treatment can be done in the furnace. If the part dimensions are abnormal, there is necessary to perform pre-heating and subsequent heat treatment of part by means of the electric heating elements (so-called muffs). However, in this case can't be used the common processing process because of high pre-heating temperatures and subsequent heat treatment. Repairs are supposed to take into account fact that there is necessary to eliminate deformation of machined surfaces and plastic stress accumulation, cause to achieve the same operational service life. Also creation of undesirable structural changes must be avoid and eliminate also. Last, but not least, there is thermal degradation of basic materials at components, which have been operated for a long-time.

\section{Experimental part}

In the own experiment was used martensitic steel GX23CrMoV12-1. Under the normal and elevated temperature, it is stainless steel alloyed by chromium $(\mathrm{Cr})$, nickel $(\mathrm{Ni})$ and manganese (Mn). Among the most important strengthening mechanisms, which take effect during high-temperature explosion of such type of heat-resisting and modified steels, there are precipitation strengthening and solid solution substitutional strengthening.

Microstructural stability of this steel is positively influenced by low coarse-rate of $\mathrm{M}_{23} \mathrm{C}_{6}$ particles. It is due to fact that during creep loading, there is growing and subsequent coarsing of these particles, whereas coarse-rate increases with the increasing $\mathrm{Cr}$ content in steels. Another creep resistance increase is done by nitrogen alloying and also due to vanadium nitride precipitation within the grain.

Thus solid solution strengthening is subsequently achieved by substitution, whereas the main influence has the increasing molybdenum content in the solid solution. It can be also substitutional strengthened by the same mechanism as using tungsten (W), as it is already used at creep resistance materials - e.g. steel P92. Moreover, there was proved that there is no reason to increase the molybdenum equivalent content in steel over the solubility limit. Higher Mo and $\mathrm{W}$ content in steels results in secondary phases precipitation which are rich in $\mathrm{Mo}$ or $\mathrm{W}-$ e.g. $\mathrm{M}_{6} \mathrm{X}$ and $(\mathrm{Fe}, \mathrm{Cr})_{2}(\mathrm{Mo}, \mathrm{W})$. So finally there is lowering of solid solution strengthening. [7,8]

Steels GX23CrMoV12-1 is suitable to be used up to temperature $600^{\circ} \mathrm{C}$, whereas its ultimate strength under creep achieves $59 \mathrm{MPa}$ for this temperature and temperature exposition for $10^{5} \mathrm{Hrs}$. They are often used as steam turbines components as can be e.g. blades, rotors or compressors in USC power plants. Such steels offer a very good ratio between strength properties and resistance against oxidation under high temperatures - all of it under relatively low cost.

In Fig. 1 is shown the structure of delivered material GX23CrMoV12-1. It is tempered martensitic material with the initial hardness $259 \mathrm{HV}$ for loading that corresponds to method HV10 acc. to ČSN EN ISO 6507-1. In Tab. 1 is shown the chemical composition of GX23CrMoV12-1 steel that was determined by spectrometer Q4 Tasman. In Tab. 2 are summarized mechanical properties of this tested material. 


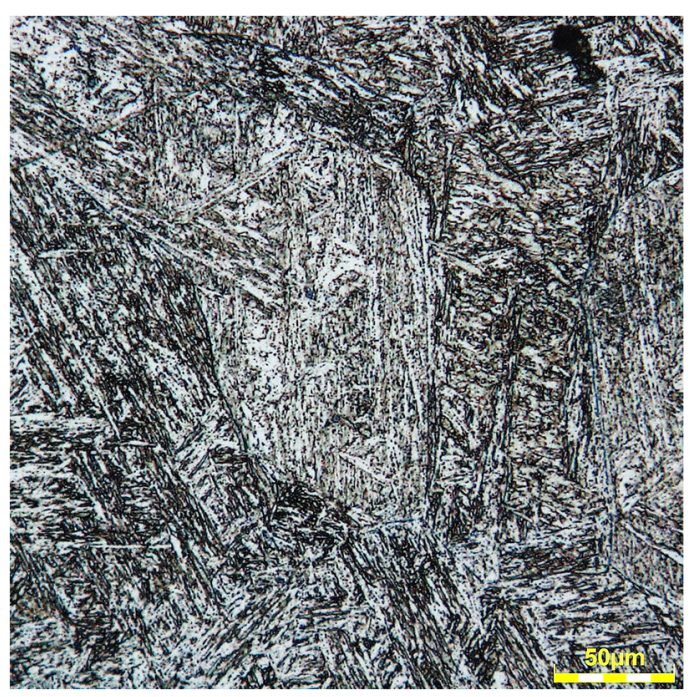

Fig. 1. Structure of tested steel GX23CrMoV12-1

Table 1. Chemical composition of GX23CrMoV12-1determined by spectrometer Q4 Tasman

\begin{tabular}{|c|c|c|c|c|c|c|c|c|}
\hline \multicolumn{7}{|c|}{ Chemical composition of GX23CrMoV12-1 [wt.\%] } \\
\hline $\mathbf{C}$ & $\mathbf{S i}$ & $\mathbf{M n}$ & $\mathbf{C r}$ & $\mathbf{M o}$ & $\mathbf{N i}$ & $\mathbf{V}$ & $\mathbf{N}$ & $\mathbf{N b}$ \\
\hline 0,238 & 0,360 & 0,609 & 11,82 & 1,148 & 1,151 & 0,301 & 0,054 & 0,007 \\
\hline
\end{tabular}

Table 2. Measured mechanical properties of delivered steel GX23CrMoV12-11

\begin{tabular}{|c|c|c|c|c|c|}
\hline \multicolumn{2}{|c|}{ Yield strength } & \multicolumn{2}{|c|}{ Ultimate strength } & \multirow{2}{*}{$\begin{array}{c}\text { Total } \\
\text { ductility } \mathrm{A}_{5} \\
\text { at } 20^{\circ} \mathrm{C}[\%]\end{array}$} & \multirow{2}{*}{$\begin{array}{c}\text { Impact } \\
\text { energy KV2 } \\
\text { at } 20^{\circ} \mathrm{C}[\mathrm{J}]\end{array}$} \\
\hline $\begin{array}{c}\mathbf{R}_{\mathrm{p} 0,2} \text { at } 20^{\circ} \mathrm{C} \\
{[\mathrm{MPa}]}\end{array}$ & $\begin{array}{c}\mathbf{R}_{\mathrm{p} 0,2} \text { at } 600^{\circ} \mathrm{C} \\
{[\mathrm{MPa}]}\end{array}$ & $\begin{array}{c}\mathbf{R}_{\mathrm{m}} \text { at } 20^{\circ} \mathrm{C} \\
{[\mathrm{MPa}]}\end{array}$ & $\begin{array}{c}\mathbf{R}_{\mathbf{m}} \text { at } 600^{\circ} \mathrm{C} \\
{[\mathrm{MPa}]}\end{array}$ & & \\
\hline 590 & 312 & 821 & 364 & 19 & 29 \\
\hline
\end{tabular}

Before the classification of welding procedures and creation WPS, there was necessary to create the preliminary repairing welding procedure pWPS that is needed to be verified in light of both welding and subsequent thermal treatment of welds. Experimental verification is done by samples, which match to repairs on real part. In this case was as sample used multilayer weld made into groove machined into workpiece having shape of plate with dimensions as following: $400 \times 150 \times 50 \mathrm{~mm}$. Groove created along the whole length of plate had depth $20 \mathrm{~mm}$, lower width of groove $15 \mathrm{~mm}$, transient radii R5 and upper width of groove $25 \mathrm{~mm}$. Groove is schematically shown in Fig. 2.

Groove was fulfilled totally by 21 runs in 7 layers over each other, whereas each layer contained 3 runs side by side. Welding was done by method 111 acc. to ISO 4063 by electrodes BÖHLER FOX 20 MVW (E CrMoV12 B 42 H5). Root layer was welded by electrodes with diameter $2.4 \mathrm{~mm}$, filling layers by electrodes with diameter $3.2 \mathrm{~mm}$ and also $4.0 \mathrm{~mm}$ and top layer by electrodes with diameter $5.0 \mathrm{~mm}$. Repairing by welding was performed by pre-heating of part on minimal temperature $420^{\circ} \mathrm{C}$ and interpass temperature $480^{\circ} \mathrm{C}$. During the whole time of repairing was temperature hold slightly over the temperature $\mathrm{M}_{\mathrm{s}}$. Pre-heating was carried out by means of resistance heating elements (muffs) connected 
to device Weldotherm 1, whereas the whole welding sample was wrapped in the insulating cotton Sibral. After welding there was a controlled cooling of sample on temperature $100^{\circ} \mathrm{C}$ to enable the complete martensitic transformation in the repair area. It was followed by heat treatment after holding time 2 Hrs.

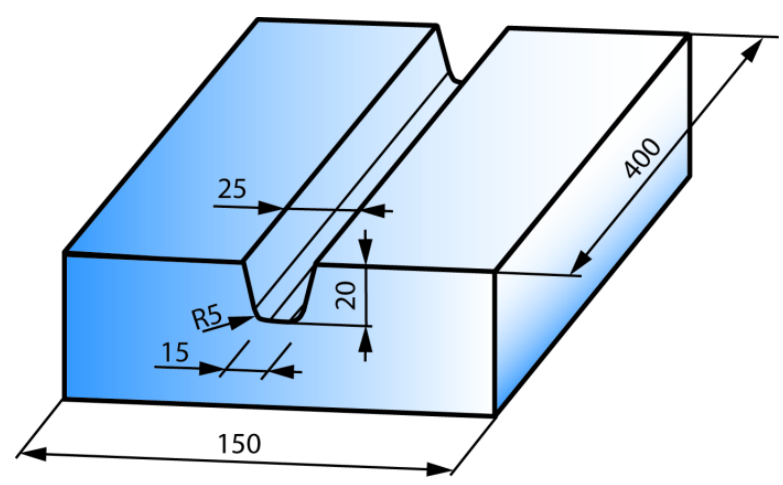

Fig. 2. Geometry of groove used for the multiple weld

In the case of standard welding procedures for steel $\mathrm{GX} 23 \mathrm{CrMoV} 12-1$ is welding followed by heat treatment that consists of heating on temperature $730^{\circ} \mathrm{C}$ and holding time on this temperature from 4 up 8 Hrs. However, in the case of repairs there can't be used so high temperature for thermal treatment due to reasons mentioned in Chap. 1. That is why there was for repairs firstly proposed to apply tempering temperature of $550^{\circ} \mathrm{C}$. To be specific, there was heating rate $100^{\circ} \mathrm{C} / \mathrm{Hr}$ on tempering temperature $550^{\circ} \mathrm{C}$, holding time 6 Hrs and subsequent cooling by cooling rate $50^{\circ} \mathrm{C} / \mathrm{Hr}$ on temperature $300^{\circ} \mathrm{C}$. Finally, sample cooled down spontaneously in wrap after that.

Properties of sample that was prepared and thermal treated as was described above were evaluated by means of hardness measurement acc. to Vickers HV10 on device Qness Q30A. From the thermal treated part were taken samples for subsequent metallographic evaluation and hardness measurement. These samples were processed by the commonly used metallographic procedure. The etchant Villela Bain was used to highlight structure. Hardness was measured in the parent material, HAZ and weld metal. Totally there were 303 incisions located in 7 longitudinal and 3 transverse lines in such manner that there was evaluated hardness in every of 7 welding layers. Incisions were done acc. to standard ČSN EN ISO 9015-1 for loading HV10 with axial distance $1 \mathrm{~mm}$. Measured values of hardness are summarized in Fig. 3. For the weld joint, magnitude of hardness in the weld metal and in HAZ should not exceed over $350 \mathrm{HV}$.

From the results is clear that tempering at temperature $550^{\circ} \mathrm{C}$ for $6 \mathrm{Hrs}$ is completely insufficient. Hardnesses in weld metal and HAZ significantly exceeded the maximal allowed magnitude of $350 \mathrm{HV}$. That is why there was decided to extend the holding time at tempering temperature $550^{\circ} \mathrm{C}$ up to $10 \mathrm{Hrs}$. However, measured results revealed that also in this case is applied thermal treatment insufficient in light of weld metal and HAZ hardness values. There was certain decrease of hardness values indeed, but it was not enough. Thus holding time was extended on $45 \mathrm{Hrs}$ because of that. Results measured under this condition are shown in Fig. 4. It flows from them that after this thermal treatment there was sufficient decrease of hardness values in weld metal, but hardness values in HAZ still exceed the maximal allowed hardness $350 \mathrm{HV}$. Due to fact that another extension of tempering time seemed to be useless, there was decided to increase tempering temperature on $580^{\circ} \mathrm{C}$ and keep the same tempering time - so 45 Hrs. In this case, measured results proved a strong decrease of hardness values in weld metal (i.e. under $350 \mathrm{HV}$ ). 


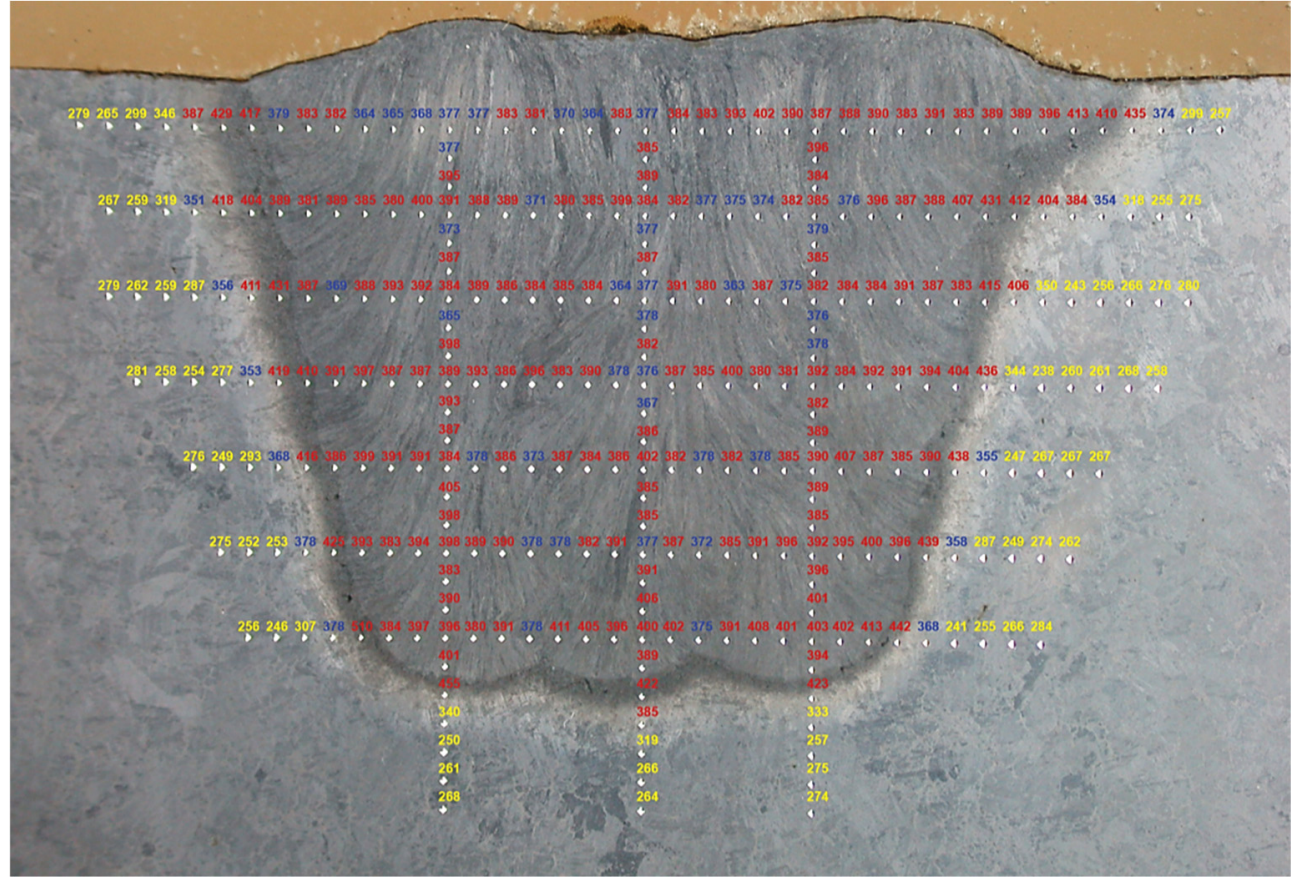

Fig. 3. Hardness values for multiple weld after welding and heat treatment at $550^{\circ} \mathrm{C}$ with holding time $6 \mathrm{Hrs}$

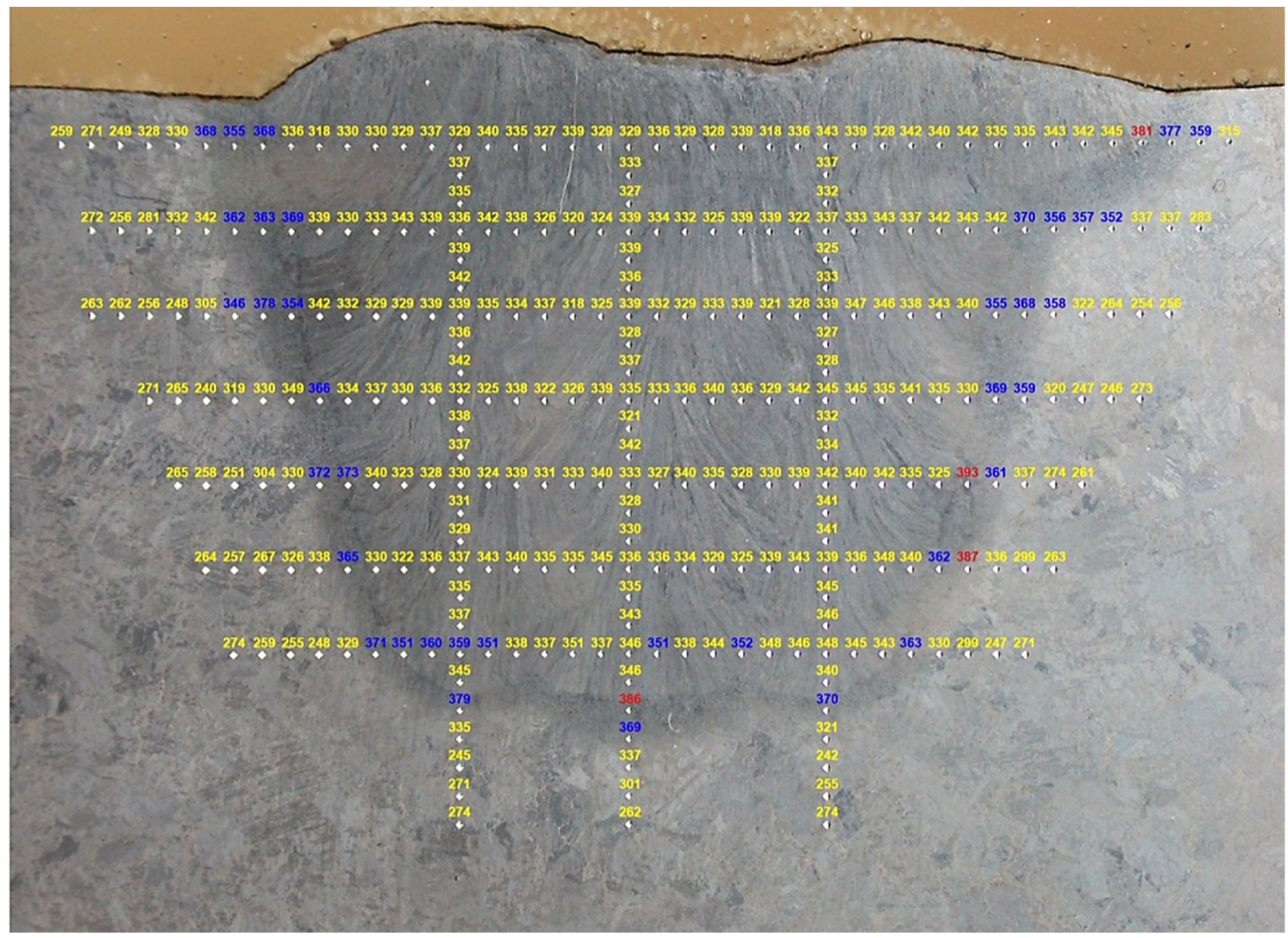

Fig. 4. Hardness values for multiple weld after welding and heat treatment at $550^{\circ} \mathrm{C}$ with holding time $45 \mathrm{Hrs}$ 


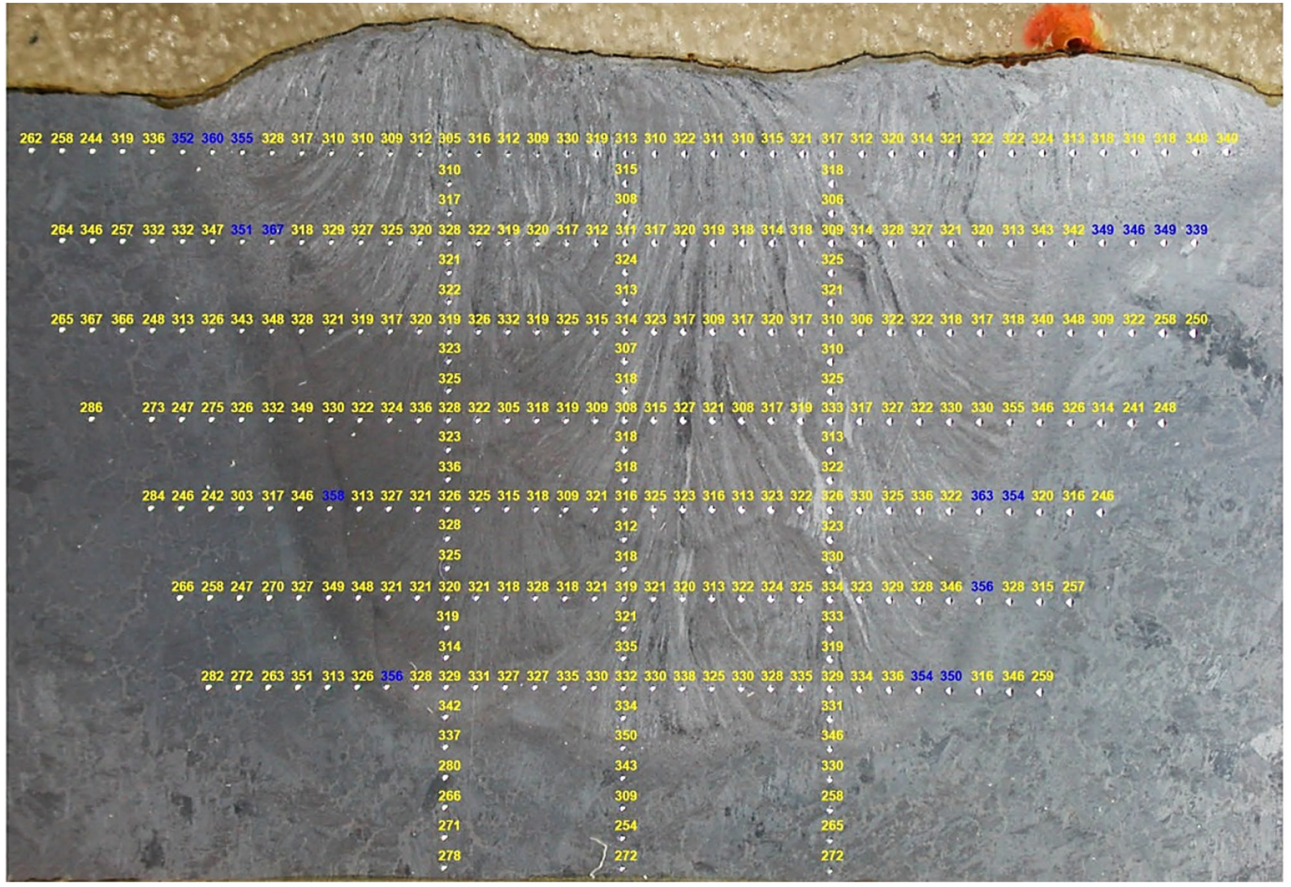

Fig. 5. Hardness values for multiple weld after welding and heat treatment at $580^{\circ} \mathrm{C}$ with holding time $45 \mathrm{Hrs}$

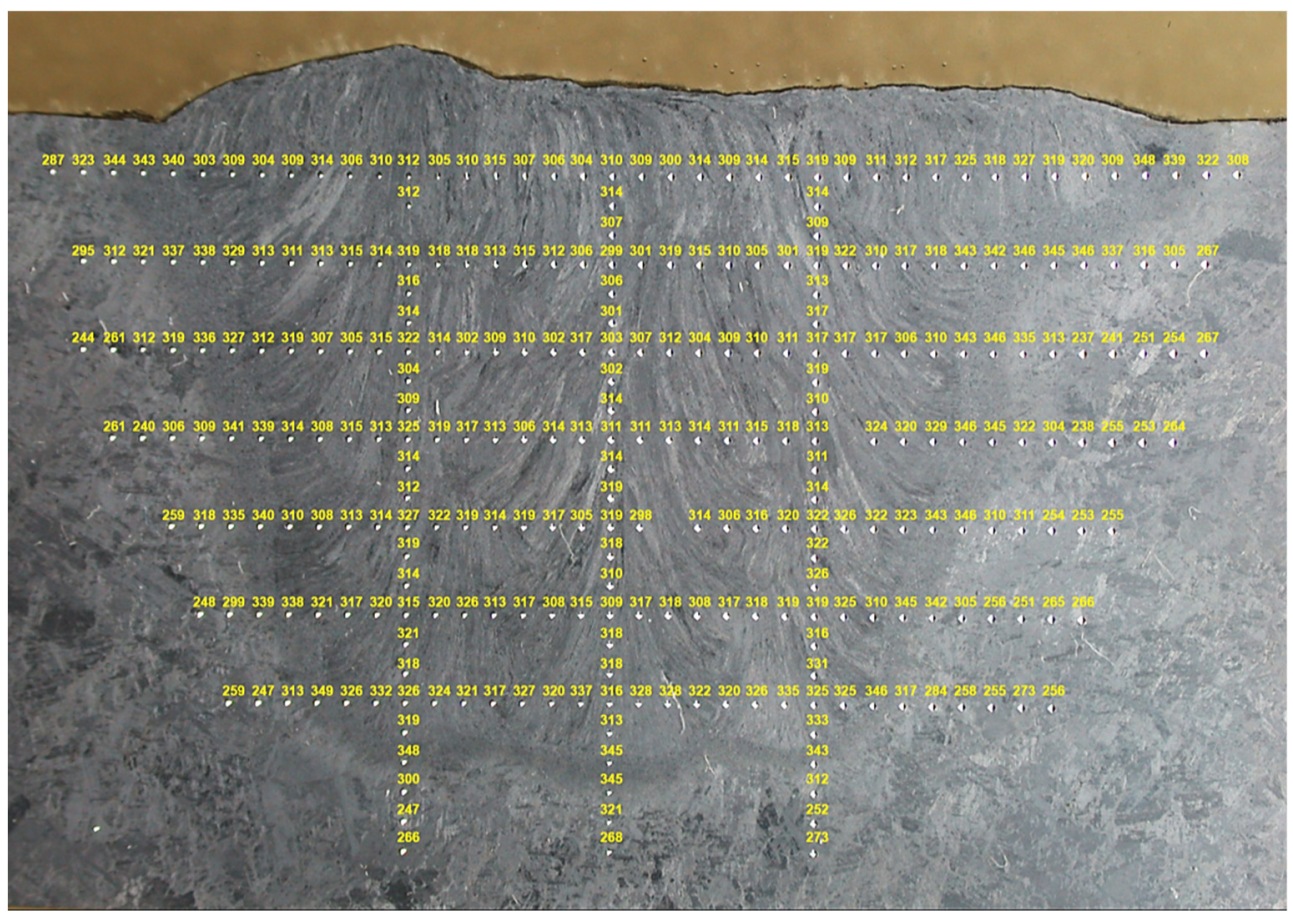

Fig. 6. Hardness values for multiple weld after welding and heat treatment at $595^{\circ} \mathrm{C}$ with holding time $45 \mathrm{Hrs}$ 
Nevertheless, hardness values in certain areas of HAZ still exceeded the required magnitude. So it means that also this approach is not fully suitable for considered repairing. So finally there was decided to increase tempering temperature once more - now up to $595^{\circ} \mathrm{C}$. In this case (see fig. 6) were for weld metal and the complete HAZ measured hardness values lower than $350 \mathrm{HV}$. In the weld metal they varied within $300 \mathrm{HV}$ and $337 \mathrm{HV}$ and in HAZ within $327 \mathrm{HV}$ up to $348 \mathrm{HV}$.

Acc. to standard ČSN ISO 148-1, these measured results should be confirmed by Charpy impact test. Positioning of testing samples in weld joint and notch orientation was performed acc. to ČSN EN ISO 9016. Samples were prepared in such manner to be tested both in HAZ (VHT 0/3) and in weld metal (VWT 0/3 and VWT 5/3). Own test was carried out on the Charpy impact tester LabTest CHK $450 \mathrm{~J}$ and always for 3 samples. Measured values of impact energy KV2 and impact toughness are summarized in Tab. 3.

Table 3. Measured values of KV2 and KCV2

\begin{tabular}{|c|c|c|c|c|c|c|}
\hline \multirow{2}{*}{$\begin{array}{c}\text { No. of } \\
\text { sample }\end{array}$} & \multicolumn{2}{|c|}{ VHT 0/3 } & \multicolumn{2}{c|}{ VWT 0/3 } & \multicolumn{2}{c|}{ VWT 5/3 } \\
\cline { 2 - 7 } & $\begin{array}{c}\text { KV2 } \\
{[\mathbf{J}]}\end{array}$ & $\begin{array}{c}\text { KCV2 } \\
{\left[\mathbf{J . c m}^{-2}\right]}\end{array}$ & $\begin{array}{c}\text { KV2 } \\
{[\mathbf{J}]}\end{array}$ & $\begin{array}{c}\text { KCV2 } \\
{\left[\mathbf{J . c m} \mathbf{- 2}^{-2}\right]}\end{array}$ & $\begin{array}{c}\text { KV2 } \\
{[\mathbf{J}]}\end{array}$ & $\begin{array}{c}\text { KCV2 } \\
{\left[\mathbf{J J . c m}^{-2}\right]}\end{array}$ \\
\hline $\mathbf{1}$ & 22 & 27.5 & 38 & 47.5 & 41 & 51.3 \\
\hline $\mathbf{2}$ & 29 & 36 & 46 & 57.5 & 33 & 41.3 \\
\hline $\mathbf{3}$ & 26 & 32.5 & 34 & 42.5 & 37 & 46.3 \\
\hline $\begin{array}{c}\text { Arithmetic } \\
\text { mean }\end{array}$ & 25 & 32 & 39 & 49 & 37 & 46.3 \\
\hline $\begin{array}{c}\text { Minimal } \\
\text { value }\end{array}$ & 22 & 27.5 & 34 & 42.5 & 33 & 41.3 \\
\hline
\end{tabular}

\section{Conclusion}

At welding $9-12 \% \mathrm{Cr}$ steels is very necessary to use not only pre-heating, but also subsequent thermal treatment at relatively high temperatures. This ensures both decreasing of residual stresses after welding and mainly carbon diffusion in martensite and thus also partial decreasing of material strength and hardness values at simultaneous increase of ductility and impact toughness. Moreover, dynamic of these processes is increasing with increasing tempering temperature.

Nevertheless, it is not possible to use tempering temperatures high enough at repairs of real parts. It is partly due to intensive oxidation on the machined parts surfaces, but mainly due to creation of deformation, which can't be removed by subsequent machining. Thus as a result, there is tendency to lower tempering temperatures as low as possible.

There was observed tempering of weld metal (created by electrodes BÖHLER FOX 20 MVW) for tested material GX23CrMoV12-1 and decrease of hardness values already under tempering temperature $550^{\circ} \mathrm{C}$ and relevant holding time $45 \mathrm{Hrs}$. Despite the partial decrease of hardness values in HAZ, their magnitudes still varied within the range of $355 \mathrm{HV}$ up to $393 \mathrm{HV}$. Lower tempering temperature couldn't decrease hardness values fast enough, as it is in the weld metal. In HAZ there represent tempering temperature $595^{\circ} \mathrm{C}$ with holding time $45 \mathrm{Hrs}$ (minimally) limit parameters for subsequent thermal treatment. By application of this thermal treatment it was possible to achieve that in the whole measuring area harness values didn't exceed over $350 \mathrm{HV}$. Also magnitudes of impact energy in weld metal were totally sufficient. These impact energies KV2 varied for test VWT 0/3 and VWT 5/3 within $33 \mathrm{~J}$ up to $46 \mathrm{~J}$. 
Also in HAZ it managed to approximate impact toughness to magnitude $29 \mathrm{~J}$ that corresponds to thermally treated parent material. From the Charpy impact test were for 3 samples achieved values as $22 \mathrm{~J}, 26 \mathrm{~J}$ and $29 \mathrm{~J}$. It already means quite good toughness under the surrounding temperature. Because the repairing components will work under temperatures about $600^{\circ} \mathrm{C}$, there can be presupposed much higher magnitude of impact toughness and so very small probability of brittle failure occurrence. Also for working temperature start and stop times would be obtained impact toughness sufficient for repairing area.

This publication was written at the Technical University of Liberec, Faculty of Mechanical Engineering with the support of the grant project MPO TRIO 10510 and with the support of the Institutional Endowment for the Long Term Conceptual Development of Research Institutes, as provided by the Ministry of Education, Youth and Sports of the Czech Republic in the year 2018.

\section{References}

1. P. Hanus, P., E. Schmídová, Influence of the Welding Process on the Martensitic and Dual Phase High Strength Steels, Manufacturing Technology, Vol. 16, 2016, pp. 702707, (2016)

2. S. Kuśmierczak, Evaluation of Degradation of Heat Stressed Pipelines. Manufacturing Technology, Vol. 15, pp. 1006-1010, (2016)

3. M. Patek, A. Sladek, M. Mician, Destructive testing of the weld joints on split sleeve for branch connections repairs. Communications - Scientific Letters of the University of Zilina, Vol. 17, Issue 4, pp. 65-69, (2015)

4. J. M. Lee, H.D. Seo, H. Chung, Efficient welding distortion analysis method for large welded structres, Journal of Materials Processing Technology, Vol. 256, June 2018, pp. 36-50, (2018)

5. J. Novotný, J. Honzíková, V. Pilous, K. Stránský, Verification for the Causes of the Degradation of Welded Joints in Power Plant. Manufacturing Technology, Vol. 16, pp. 1106-1110, (2016)

6. M. Mičian, M. Patek, A. Sládek, Concept of repairing branch pipes on high-pressure pipelines by using split sleeve. Manufacturing Technology, Vol. 14(1), pp. 60-66, (2014)

7. J. Koukal, M. Sondel, D. Schwarz, V. Foldyna, Development and microstructure of advanced creep resistant ferritic steels. International Journal of Microstructure and Materials Properties, Vol. 6, Issue 1-2, May 2011, pp. 122-131, (2011).

8. P. Mohyla, L. Havelka, K. Kouřil, Mechanical properties testing of P92 welded joints prepared by manual metal arc welding. Tehnicki Vjesnik, Vol. 25, Issue 1, February 2018, pp. 60-63, (2018) 